\title{
Fasting-induced adipose factor identified as a key adipokine that is up-regulated in white adipose tissue during pregnancy and lactation in the rat
}

\author{
Tracy Josephs ${ }^{1}$, Hayley Waugh ${ }^{1}$, Ilona Kokay ${ }^{2}$, David Grattan ${ }^{2}$ and Mary Thompson ${ }^{1}$ \\ Departments of ${ }^{1}$ Biochemistry and ${ }^{2}$ Anatomy and Structural Biology, Otago School of Medical Sciences, University of Otago, PO Box 56, Dunedin 9054, \\ New Zealand \\ (Requests for offprints should be addressed to M Thompson; Email: mary.thompson@stonebow.otago.ac.nz)
}

\begin{abstract}
Adipokines, which are expressed and secreted from white adipose tissue (WAT), are potential factors that could contribute to the changes in energy homeostasis that occurs in pregnancy and lactation to meet the nutrient demands of fetal growth and milk production. The aim was to identify adipokines that could be involved by measuring the pattern of their mRNA expression in adipose tissue. Adipokine mRNAs were measured by quantitative RT-PCR in RNA isolated from white and brown adipose tissue (BAT) of rats at days 7, 14 and 21 of pregnancy, day 7 of lactation and virgin at dioestrus phase. The results for leptin, adiponectin and resistin expression in WAT essentially confirmed previous studies and it is unlikely that they are directly involved in the metabolic adaptations. The relative amounts of the mRNAs of the
\end{abstract}

adipokines in BAT were comparable with those in WAT, but the patterns of expression did not follow those in WAT, except for apelin. Visfatin mRNA in WAT was elevated 2.5fold only at day 21 of pregnancy. Apelin mRNA in WAT was increased $2 \cdot 2$-fold at day 7 of pregnancy. Retinol-binding protein 4 mRNA in WAT decreased to $46 \%$ of control at day 14 of pregnancy. Fasting-induced adipose factor (FIAF) mRNA in WAT was $2 \cdot 2$ - to $2 \cdot 5$-fold higher throughout pregnancy and lactation. The marked induction of FIAF identifies this adipokine as a potential regulator of the metabolic adaptations that occur during pregnancy and lactation.

Journal of Endocrinology (2007) 194, 305-312

\section{Introduction}

Pregnancy and lactation are physiological situations where major changes in energy homeostasis occur to meet the nutrient demands of fetal growth and milk production. The energy needs are met by increased food intake and/or mobilisation of stored fuels. Maternal metabolism is directed towards supplying adequate nutrients for the fetus. Pregnancy is characterised by a series of metabolic changes that promote increased adipose tissue mass in early pregnancy, with marked increases in food intake and a decreased sensitivity of maternal tissues to insulin. This change in insulin sensitivity allows for decreased glucose utilisation and a shift to fat metabolism by maternal peripheral tissues and increased availability to the feto-placental unit. There is also an increase in plasma of both triglycerides and free fatty acids. During lactation metabolic changes take place to direct substrates away from storage to the mammary gland for milk production and fat mobilisation from adipose tissue occurs despite increased food intake (Williamson \& Lund 1994, Herrera 2000, Di Cianni et al. 2003). The pregnant state parallels the insulin-resistant states of obesity and type 2 diabetes, which are also characterised by insulin resistance, and can become manifested as gestational diabetes in humans (Di Cianni et al. 2003).

The molecular mechanisms governing these integrated alterations in metabolism are still far from known. Initial data pointed to alterations in pregnancy-related hormones, such as oestrogen, progesterone and prolactin, as potential mediators of insulin resistance in pregnancy. However, the effects of these hormones do not fully account for the metabolic adaptations that occur. More recently, adipokines have emerged as potential factors that could contribute to energy homeostasis in pregnancy and lactation.

White adipose tissue (WAT) is now strongly established as an endocrine tissue that produces a number of adipokines that serve as feedback signals to regulate WAT metabolism as well as having effects on food intake, energy expenditure, and carbohydrate and lipid metabolism (Trayhurn 2005, Ronti et al. 2006). These adipokines include leptin, adiponectin and resistin: leptin inhibits food intake and stimulates energy expenditure; adiponectin increases insulin sensitivity and stimulates fatty acid oxidation, whereas resistin may contribute to insulin resistance. In the light of this, considerable effort is being put into determining whether these adipokines 
have a role in the regulation of homeostasis during pregnancy and lactation (Henson \& Castracane 2000, Reitman et al. 2001, Catalano et al. 2006). Hyperleptinaemia occurs from mid to late pregnancy in rodents (Chein et al. 1997, Kawai et al. 1997, Tomimatsu et al. 1997, Amico et al. 1998, López-Soriano et al. 1998, García et al. 2000, Herrera et al. 2000, Mistry \& Romsos 2002, Seeber et al. 2002, Ramos et al. 2003, Ladyman \& Grattan 2004) and humans (Butte et al. 1997, Mukherjea et al. 1999). However, it is debatable whether the hyperleptinaemia contributes to the metabolic adaptations; it is more likely that it is caused, at least in part, by the increase in total WAT mass rather than being an adaptive response to pregnancy. In fact a state of pregnancy-induced central leptin resistance appears to occur to allow the increased food intake despite the elevated leptin (Ladyman \& Grattan 2004). Plasma levels of adiponectin have been reported to decline in late pregnancy in mice (Combs et al. 2003) and humans (Catalano et al. 2006), which is consistent with the decreased insulin sensitivity of the pregnant state. There is some evidence that dysregulation of leptin and adiponectin correlate with changes in pathologies of pregnancy, such as gestational diabetes. Women with gestational diabetes have elevated leptin levels (KautzkyWiller et al. 2001), whereas adiponectin levels are decreased when compared with normal pregnancies (Worda et al. 2004, Thyfault et al. 2005); this is similar to other insulin-resistant states, although the physiological significance of these changes is still debated.

Many other adipokines that have recently been identified in WAT have not been studied in relation to pregnancy and lactation. These other adipokines, which include fastinginduced adipose factor (FIAF), visfatin, apelin and retinolbinding protein 4 (RBP4), are also expressed in a nutritionally dependent manner or have been implicated in some way with the state of insulin resistance. FIAF, also known as angiopoietin-like protein 4, was initially discovered as a novel target for peroxisome proliferator-activated receptor (Kersten et al. 2000, Yoon et al. 2000) and as hepatic fibrinogen/angiopoietin-related protein (Kim et al. 2000). FIAF is expressed in WAT and its expression is highly up-regulated by fasting and elevated in monogenetic rodent models of obesity (Yoon et al. 2000). Serum levels of FIAF in human subjects are inversely correlated with insulin resistance in type 2 diabetes ( $\mathrm{Xu}$ et al. 2005). Apelin is a recently identified adipokine that is expressed and secreted from WAT and a number of other tissues including heart and kidney. Apelin expression in WAT is reduced by fasting and restored by refeeding and plasma levels of apelin are increased in obesity associated with hyperinsulinaemia (Boucher et al. 2005). Visfatin was identified as a transcript preferentially expressed in visceral WAT although not exclusively (Fukuhara et al. 2005). Visfatin expression increases during the development of obesity and is up-regulated in rodent models of obesity and human insulin-resistant states such as type 2 diabetes (Chen et al. 2006). Interestingly, visfatin has insulinomimetic effects via binding to the insulin receptor at sites distinct from insulin (Fukuhara et al. 2005). RBP4 has joined the growing list of WAT-derived factors that can modulate energy homeostasis (Yang et al. 2005). RBP4 expression is elevated in several rodent models of obesity and insulin resistance and plasma levels correlate with the magnitude of insulin resistance in humans with obesity and type 2 diabetes (Cho et al. 2006, Graham et al. 2006). Despite the strong connection of all these newly identified adipokines with the regulation of energy homeostasis they have not been studied in normal pregnancy and lactation, a physiological situation where marked changes in metabolism occur to maintain energy homeostasis. It might be expected that adipokines that respond to fasting and feeding may be regulated coordinately during pregnancy and lactation, two physiological states that mirror aspects of the fed and the fasted states.

This study aimed to quantitatively measure the relative amounts of mRNA in WAT of four of the newly identified adipokines, FIAF, visfatin, apelin and RBP4, in order to determine whether any of them may have a role in pregnancy and lactation. The patterns of expression in WAT during pregnancy and lactation in the rat were compared with those of the well-established adipokines, leptin, adiponectin and resistin. In addition, a number of these adipokines have already been shown to be expressed in brown adipose tissue (BAT): leptin (Zhang et al. 2002), adiponectin (Zhang et al. 2002, Combs et al. 2003), resistin (Kim et al. 2001), FIAF (Kersten et al. 2000, Yoon et al. 2000) and apelin (Boucher et al. 2005), but the significance of this is not known. This study also aimed to quantitate the expression of the adipokines in BAT and determine whether their patterns of expression follow those in WAT.

\section{Materials and Methods}

\section{Animals and tissue samples}

Animals were obtained from the colony at the University of Otago. Thirty female Sprague-Dawley rats were obtained at 9-10 weeks of age and housed under a $14 \mathrm{~h}$ darkness cycle. Temperature was maintained at $22 \pm 1{ }^{\circ} \mathrm{C}$, and all rats had ad libitum access to food and water. Rats were weight matched and weighed between 250 and $300 \mathrm{~g}$. Cervical smearing of rats was used to determine their cycling. Rats that were deemed to be in pro-oestrus were housed overnight with a male rat and smeared the following day to detect sperm. The presence of sperm was taken as day 0 of pregnancy and the day of delivery was taken as day 1 of lactation. The rats in the lactation group had their litter number normalised to ten on day 2 of lactation. There were six animals in each experimental group and a control group of non-pregnant rats at dioestrus. At relevant time points in pregnancy (days 7, 14 and 21) or lactation (day 7) the rats were killed by decapitation and parametrial WAT and interscapular BAT samples were rapidly removed and frozen in liquid nitrogen and stored at $-80{ }^{\circ} \mathrm{C}$ until used. All animal experimental 
protocols were approved by the University of Otago committee on ethics in the care and use of laboratory animals.

\section{RNA isolation}

Total RNA was isolated from WAT tissues using TRIZOL reagent (Invitrogen) and following the manufacturer's instructions, with an additional precipitation step included where the final pellet was redissolved in $4 \mathrm{M}$ guanidine thiocyanate and reprecipitated in $1 \mathrm{ml}$ isopropanol overnight at $-20^{\circ} \mathrm{C}$. RNA was isolated from BAT following the manufacturer's instructions. Upon isolation, RNA was stored at $-80^{\circ} \mathrm{C}$. The yield and quality of the RNA were assessed by the $260 / 280 \mathrm{~nm}$ optical density ratio.

\section{cDNA synthesis}

Total RNA was treated with RNase-free DNase I (Invitrogen) for $10 \mathrm{~min}$ at $37^{\circ} \mathrm{C}$ and a further $10 \mathrm{~min}$ at $75^{\circ} \mathrm{C}$ to remove any genomic contamination. cDNA was synthesised from $1 \mu \mathrm{g}$ DNase-treated RNA using random primers (5 ng/ $\mu \mathrm{l}$ ) and Moloney murine leukaemia virus reverse transcriptase (MMLV-RT; Invitrogen) in a final volume of $20 \mu \mathrm{l}$. Negative control samples were prepared by performing reverse transcription reactions in the absence of MMLV-RT. WAT and BAT cDNA samples were kept at $-20^{\circ} \mathrm{C}$ until analysis by quantitative real-time PCR.

\section{Quantitative RT-PCR analysis}

Quantitative RT-PCR analyses were performed in a Lightcycler (Roche) according to the manufacturer's instructions. Total cDNA was diluted in the ratio of 1:10 for WAT samples and in the ratio of 1:5 for BAT samples for all the analyses, except $18 \mathrm{~S}$ rRNA when WAT and BAT samples were diluted in the ratio of $1: 100$. The $20 \mu \mathrm{l}$ amplification mixture contained $3 \mu \mathrm{l}$ diluted $\mathrm{RT}$ reaction (cDNA) plus $0.5 \mu \mathrm{mol} / 1$ each primer (Table 1) and $1 \times$ LightCycler FastStart DNA

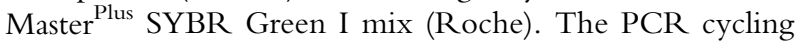
conditions included an initial denaturation at $95^{\circ} \mathrm{C}$ for $10 \mathrm{~min}$ followed by 40 cycles at $95^{\circ} \mathrm{C}$ for $10 \mathrm{~s}, 5 \mathrm{~s}$ at $55^{\circ} \mathrm{C}$ and $10 \mathrm{~s}$ at $72^{\circ} \mathrm{C}$. The specificity of the amplifications was confirmed by melt analysis. Standard curves were prepared from a series of tenfold dilutions of pooled WAT cDNA. The errors of the standard curves were $0 \cdot 013,0 \cdot 018,0 \cdot 006,0 \cdot 006$, $0 \cdot 015,0 \cdot 002$ and $0 \cdot 014$, for leptin, adiponectin, resistin, FIAF, apelin, RBP4 and visfatin respectively. The amplification efficiencies were $1.75,1.81,1.98,1.95,1.96,1.87$ and 1.99 for leptin, adiponectin, resistin, FIAF, apelin, RBP4 and visfatin respectively. Relative amounts of mRNA were calculated using Lightcycler Software version 4.0 (Roche). The values obtained from the standard curves were normalised on the basis of the corresponding $18 \mathrm{~S}$ rRNA quantification and then calculated relative to the control samples from non-pregnant rats in dioestrus set at 1.0. Samples were analysed in duplicate. For all samples no amplification occurred in reverse-transcription negative controls and single amplicons of the correct size were obtained. Amplicons were sequenced to verify authenticity.

\section{Statistical analysis}

Instat (GraphPad Inc., San Diego, CA, USA) was used to compare pregnant and lactating adipokine mRNA expression with non-pregnant adipokine mRNA expression. All data are expressed as the mean \pm s.E.M., and six animals were used in each experimental group. Differences between groups were evaluated using one-way ANOVA, using a Student-Newman-Keuls test for post hoc comparisons. The level of significance for all tests was set at $P<0 \cdot 05$.

\section{Results}

\section{$m R N A$ expression of adipokines in WAT and BAT}

The relative amounts of mRNA of a repertoire of adipokines were measured in the same WAT and BAT samples from rats at different stages of pregnancy and lactation and compared with control levels measured in samples from virgin rats at dioestrus phase. Leptin, adiponectin and resistin were measured to confirm previous published data and to provide patterns of expression to which other adipokines could be compared.

The relative amounts of mRNA of the adipokines, leptin, adiponectin and resistin are given in Fig. 1. Leptin mRNA in WAT increased by mid pregnancy and significantly increased by $1 \cdot 8$-fold at day 21 of pregnancy and decreased to control levels by day 7 of lactation. The changes in leptin mRNA in BAT did not reach statistical significance (Fig. 1A). The expression of adiponectin mRNA in WAT did not change significantly over the course of pregnancy and lactation, although in BAT adiponectin mRNA tended to be higher during pregnancy than in controls (Fig. 1B). Resistin mRNA in WAT decreased to $40 \%$ of control levels at day 14 of pregnancy and to only $16 \%$ of control levels at day 21 of pregnancy and were still at $44 \%$ of control levels at day 7 of lactation. In contrast, the expression of resistin mRNA in BAT exhibited a pattern opposite to that seen in WAT. The relative amount of resistin mRNA in BAT increased 2.5-fold at day 14 of pregnancy and tended to be elevated at day 21 of pregnancy, whereas in WAT it was lower than normal (Fig. 1C).

The relative amounts of mRNA for the newly identified adipokines are given in Fig. 2. FIAF mRNA in WAT were increased throughout pregnancy and lactation, with a $2 \cdot 5$-fold increase at day 7 , a 2·3-fold increase at day 14 and a 3·1-fold increase at day 21 of pregnancy. There was a $2 \cdot 2$-fold increase in FIAF mRNA in WAT at day 7 of lactation. These were the most marked changes for all the adipokine mRNAs that were measured. In BAT an increased relative amounts of FIAF mRNA was seen only at day 14 of pregnancy (Fig. 2A). 
Table 1

Genbank accession no.

\begin{tabular}{|c|c|c|}
\hline \\
\hline $\begin{array}{l}\text { Gene } \\
18 S r R N A\end{array}$ & M11188 & $\begin{array}{l}\text { Forward } \\
\text { Reverse }\end{array}$ \\
\hline Adiponectin & NM144744 & $\begin{array}{l}\text { Forward } \\
\text { Reverse }\end{array}$ \\
\hline Apelin & NM031612 & $\begin{array}{l}\text { Forward } \\
\text { Reverse }\end{array}$ \\
\hline FIAF & NM199115 & $\begin{array}{l}\text { Forward } \\
\text { Reverse }\end{array}$ \\
\hline Leptin & NM013076 & $\begin{array}{l}\text { Forward } \\
\text { Reverse }\end{array}$ \\
\hline RBP4 & XM215285 & $\begin{array}{l}\text { Forward } \\
\text { Reverse }\end{array}$ \\
\hline Resistin & NM144741 & $\begin{array}{l}\text { Forward } \\
\text { Reverse }\end{array}$ \\
\hline Visfatin & NM177928 & $\begin{array}{l}\text { Forward } \\
\text { Reverse }\end{array}$ \\
\hline
\end{tabular}

Primer sequences $\left(5^{\prime}-3^{\prime}\right)$

Size of Amplicon (bp)

TACCGCAGCTAGGAATAATGG

CGGAACTACGACGGTAT

TAATCCTGCCCAGTCATGAAG

CATCTCCTGGGTCACCCTTA

GAAGAAGGCAACATGCGCTAC

ACTTGGAGAGCCCTTCAATCCT

CTCTGGGATCTCCACCATTT

TTGGGGATCTCCGAAGCCAT

AAGACCATTGTCACCAGGATCAA

GGTCCATCTTGGACAAACTCAGA

TGGTATGCCATCGCCAAAA

TTCCCAGTTGCTCAGAAGACG

GCTCTCTGCCACGTACTTA

TTCATTGCAGCTGGCAGTAG

AGCGGCAGAGCACAGTACCATA

CCACAGACACAGGCACTGATGA
229

216

157

140

124

135

170

101

FIAF, fasting-induced adipose factor; RBP4, retinol-binding protein.

The relative amounts of visfatin mRNA in WAT were increased $2 \cdot 4$-fold only at day 21 of pregnancy and then returned to control levels at day 7 of lactation. This pattern was similar to that seen for leptin. In BAT, instead of an increase, the relative amounts of visfatin mRNA at day 21 of pregnancy and also at day 7 of lactation were lower than those during early and mid pregnancy (Fig. 2B).

The relative amounts of apelin mRNA in WAT increased $2 \cdot 2$-fold at day 7 of pregnancy and returned to control levels at day 14 and were at control levels for the remainder of pregnancy. At day 21 of pregnancy and day 7 of lactation apelin mRNA tended to be lower than controls but this did not reach statistical significance. In BAT, the pattern of expression of apelin mRNA throughout pregnancy and lactation was similar to that seen in WAT (Fig. 2C).

In contrast to the other adipokines, the relative amounts of RBP4 mRNA in WAT decreased to $46 \%$ of control levels at day 14 of pregnancy and returned to near control levels at day 21 of pregnancy. The relative amounts of RBP4 mRNA in BAT also decreased to $29 \%$ of control levels but not until day 21 of pregnancy and then returned to control levels at day 7 of lactation (Fig. 2D).

\section{Expression of adipokines in BAT when compared with WAT}

In this study it has been possible to accurately compare the relative amounts of mRNA expression of each adipokine in BAT with that in WAT as the quantitation was performed using a standard curve prepared from cDNA generated from WAT RNA. WAT and BAT showed similar relative amounts of mRNA for FIAF, apelin and RBP4 $(1 \cdot 4,1.5$ and 1.0 respectively). There was $25 \%$ less resistin mRNA expression in BAT relative to WAT. The expression of adiponectin and leptin mRNAs was higher in BAT when compared with WAT $(2 \cdot 8$ - and $2 \cdot 5$-fold respectively). There was $4 \cdot 7$-fold more visfatin mRNA in BAT when compared with WAT. This is the first report of RBP4 and visfatin expression in BAT. Overall, the patterns of expression throughout pregnancy and lactation in BAT did not follow those seen in WAT, except for apelin (Figs 1 and 2). For resistin and RBP4, instead of a decreased expression of mRNA in late pregnancy as seen in WAT, there was an increase in expression in BAT. The elevation of visfatin and leptin in WAT at day 21 of pregnancy was not seen in BAT.

\section{Discussion}

This study quantitatively measured the relative amounts of mRNA expression of a selected repertoire of adipokines in the same WAT and BAT samples from rats at different stages of pregnancy and lactation. The results for the expression in WAT of leptin, adiponectin and resistin essentially confirm previous studies. The present study showed significantly elevated leptin mRNA in WAT in late pregnancy. This finding is very similar to those reported for rats (Kawai et al. 1997, García et al. 2000) and for mice (Tomimatsu et al. 1997). In studies where the plasma leptin concentration was also measured, for rats the magnitude of increase in plasma reflected that seen for the mRNA (Kawai et al. 1997, García et al. 2000), but for mice the plasma leptin increased more markedly than the mRNA (Tomimatsu et al. 1997). Adiponectin mRNA in WAT was unchanged, which is in agreement with a report by Caja et al. (2005b) which found adiponectin mRNA and plasma concentration remained unchanged during pregnancy. However, for mice, Combs et al. (2003) has reported a progressive decrease in plasma adiponectin concentration towards the end of pregnancy and during lactation in mice, with Kondo et al. (2004) reporting a decrease in adiponectin mRNA levels in WAT of pregnant 
A Leptin

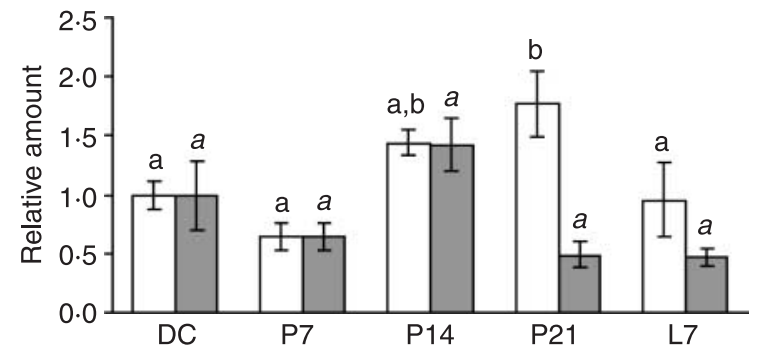

B Adiponectin

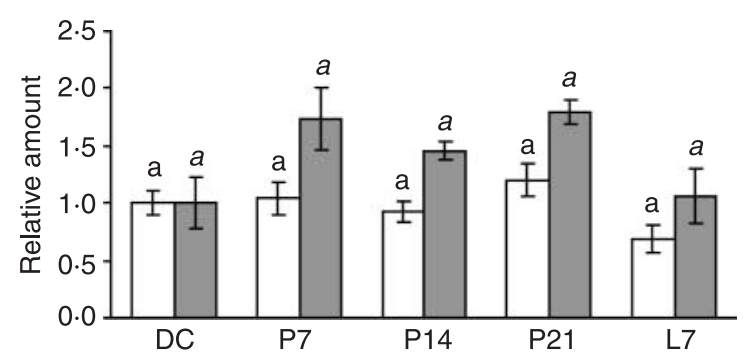

C Resistin

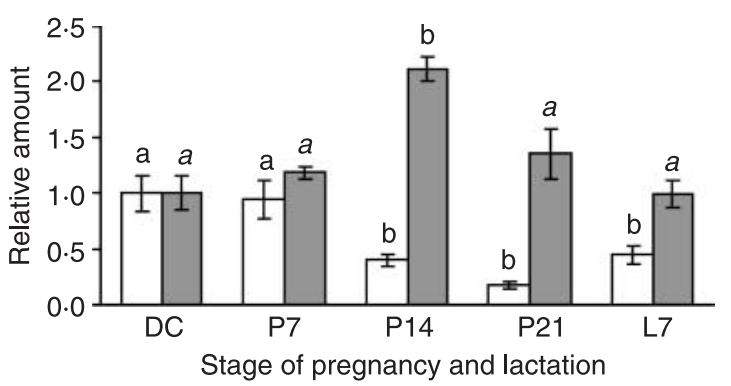

Figure 1 Expression of leptin, adiponectin and resistin in white adipose tissue (white bars) and brown adipose tissue (grey bars) from rats in pregnancy and lactation. Samples were from day 7 (P7), 14 (P14) and 21 (P21) of pregnancy and day 7 (L7) of lactation. Controls (DC) were obtained from non-pregnant rats in dioestrus phase. Samples were removed, RNA was extracted and cDNA was generated from $1 \mu \mathrm{g}$ RNA and used to determine the relative amounts of mRNA by quantitative PCR. Values were normalised to $18 \mathrm{~S}$ rRNA and expressed relative to controls set at $1 \cdot 0$. Bars represent the mean \pm S.E.M. of six animals. Within WAT and BAT, samples with different superscript letters are significantly different $(P<0 \cdot 05)$

mice. These observations suggest that there are species differences in the response of adiponectin to pregnancy. There have been two papers, in addition to the present study, reporting resistin mRNA expression in WAT during pregnancy (Nogueiras et al. 2003, Caja et al. 2005a). They reported elevated resistin mRNA in WAT in early pregnancy and a decrease in late pregnancy. In the present study, the early elevation in resistin mRNA was not observed but a marked decrease by day 21 confirms the published data that resistin mRNA expression declines as pregnancy progresses. At mid
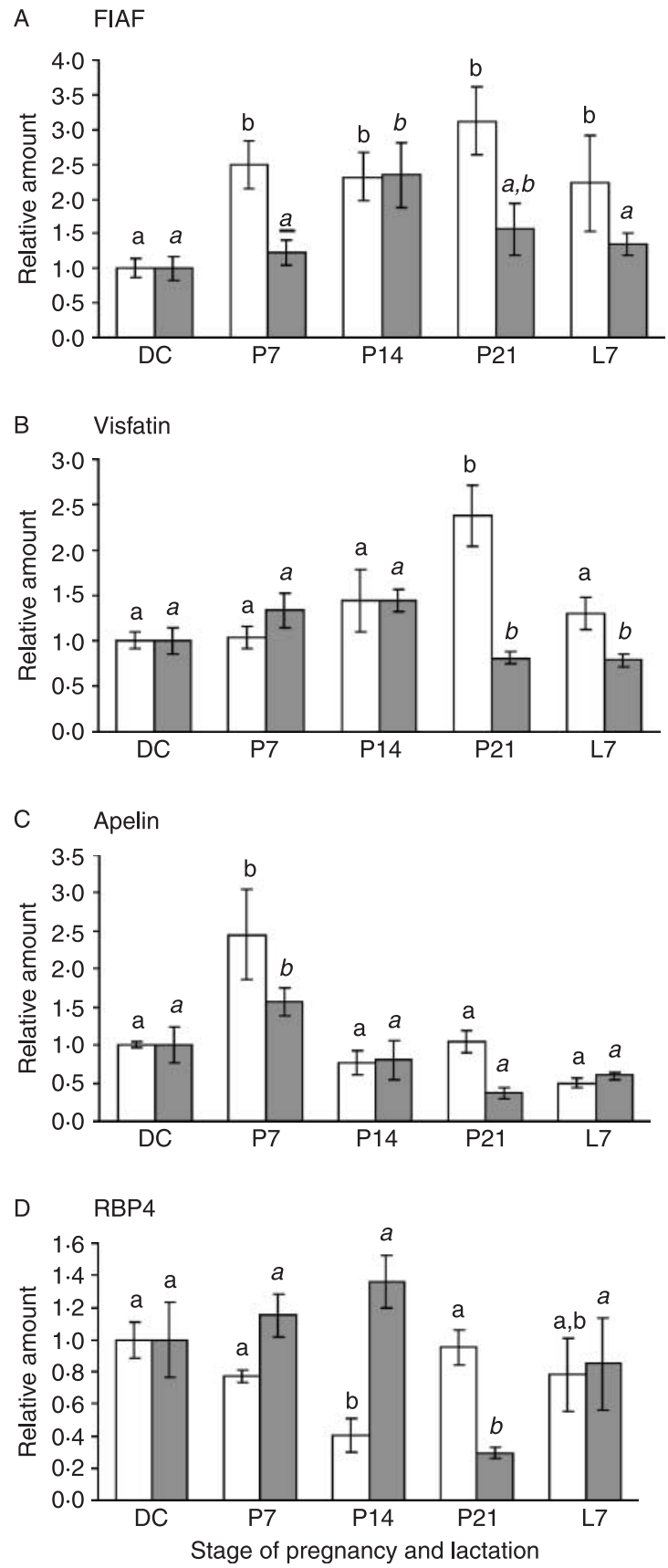

Figure 2 Expression of FIAF, visfatin, apelin and RBP4 in white adipose tissue (white bars) and brown adipose tissue (grey bars) from rats during pregnancy and lactation. Samples were from day 7 (P7), 14 (P14) and 21 (P21) of pregnancy and day 7 (L7) of lactation. Controls (DC) were obtained from non-pregnant rats in dioestrus phase. Samples were removed, RNA was extracted and cDNA was generated from $1 \mu \mathrm{g}$ RNA and used to determine relative amounts of mRNA by quantitative PCR. Values were normalised to $18 \mathrm{~S}$ rRNA and expressed relative to controls set at $1 \cdot 0$. Bars represent the mean \pm s.E.M. of six animals. Within WAT and BAT, samples with different superscript letters are significantly different $(P<0 \cdot 05)$. 
lactation resistin expression was still low, although in lactating mice Bing et al. (2002) reported that resistin mRNA in WAT was unchanged when compared with non-pregnant mice. Taken together, it appears that leptin, adiponectin and resistin are not playing obvious roles in the metabolic adaptations that occur in normal pregnancy and lactation. The development of insulin resistance in late pregnancy (Ramos et al. 2003) does not appear to be accompanied by the expected decrease in adiponectin expression and increase in resistin expression as occurs in other insulin-resistant states (Steppan et al. 2001, Weyer et al. 2001). However, major changes in their expression may signal pathological states such as gestational diabetes (Kautzky-Willer et al. 2001, Worda et al. 2004, Thyfault et al. 2005). To date, other adipokines have essentially been overlooked with respect to a possible role in pregnancy and lactation.

This is the first report of changes in the mRNA expression of the newly identified adipokines, FIAF, visfatin, apelin and $\mathrm{RBP} 4$, in WAT and BAT during pregnancy and lactation. It is likely that changes in mRNA are reflected by corresponding changes in plasma protein concentrations, although confirmation of this awaits further investigations. Nevertheless, changes in the relative amounts of mRNA do indicate that regulation is occurring at the level of gene transcription or mRNA turnover and therefore may be of physiological significance. The changes may be a consequence of pregnancy or lactation and/or involved in the metabolic adaptations themselves. It was expected that adipokines that are up-regulated in obesity and insulin-resistant states would also be up-regulated during the pregnant state, which is also characterised by increased WAT mass and insulin resistance. Surprisingly, no clear-cut patterns directly related to the state of insulin resistance emerged.

The relative amount of apelin mRNA only increased in early pregnancy so it appears that apelin expression is not associated with the hyperinsulinaemia of pregnancy, although it has been reported to be associated with the hyperinsulinaemia of obesity (Boucher et al. 2005). The reason for the increase in early pregnancy is not known, but may be associated with fat accumulation.

The relative amount of visfatin mRNA increased in late pregnancy and this pattern was similar to that seen for leptin mRNA. There is evidence to suggest that both these adipokines can counteract insulin resistance (Buettner et al. 2000, Fukuhara et al. 2005) so it is possible that the increase in late pregnancy is an attempt to counteract insulin resistance as the rat enters lactation.

Contrary to expectations, RBP4 expression did not increase at a stage in pregnancy when insulin resistance is manifest, rather the relative amount of RBP4 mRNA was lowest at mid pregnancy. Another adipokine, resistin, which is also attributed with contributing to insulin resistance (Steppan et al. 2001), was also expressed at a lower level in late pregnancy. Perhaps, rather than contributing to insulin resistance their down-regulation may actually limit the degree of the insulin resistance, which occurs as a necessary adaptive response to pregnancy.

The most striking change in expression was seen for FIAF; the relative amounts of FIAF mRNA were two- to threefold higher in WAT throughout pregnancy and lactation compared with control. What makes FIAF of particular interest here is that it is acutely and markedly induced by fasting and down-regulated by feeding (Kersten et al. 2000, Yoon et al. 2000), and hence it is surprising that FIAF expression is up-regulated in pregnancy and lactation, which are characterised by hyperphagia. However, the demand for fuels is greater in these states and FIAF expression may be responsive to signals of energy demand. There are compelling data to link FIAF with the regulation of lipid and glucose metabolism. Overexpression of FIAF and injection of recombinant FIAF in mice brings about an increase in plasma of both triglycerides and free fatty acids (Yoshida et al. 2002, $\mathrm{Xu}$ et al. 2005, Mandard et al. 2006), due to both decreased clearance of lipoproteins and stimulated lipolysis (Mandard et al. 2006). The combination of elevated triglycerides as well as free fatty acids also marks the pregnant state, but this does not reflect a pathological condition, rather a necessary adaptation to meet the energy demands of the fetus and to prepare for lactation. WAT mass increases during pregnancy but there is an enhanced maternal lipolytic activity during late pregnancy to provide free fatty acids for maternal tissues (Ramos et al. 2003). The finding that FIAF mRNA expression is greatly up-regulated during pregnancy and lactation is novel and suggests a possible mechanism to promote the use of fatty acids as a fuel by maternal tissues and spare glucose for the fetus. It is possible to speculate that FIAF may be an important factor produced to help alleviate the excesses of hyperglycaemia and hyperinsulinaemia as would occur in gestational diabetes, and at the same time help to switch maternal metabolism towards lipids and to prepare for lactation. These possibilities remain to be tested. Interestingly, adenovirus-mediated expression of FIAF alleviated glucose intolerance and hyperinsulinaemia in wild-type and $d b / d b$ diabetic mice (Xu et al. 2005), although this effect was not seen in mice transgenic for FIAF (Mandard et al. 2006).

The expression of the adipokines in BAT was comparable to that in WAT, which was surprising considering the different physiological roles for which the two tissues are adapted. Even though all the adipokines studied are expressed in BAT, this tissue is not likely to be a major contributor to the total circulating pool of the adipokines.

Lactation is probably the best characterised physiological situation associated with an adaptive decrease in BAT thermogenesis (Trayhurn et al. 1982), yet there was no change in adipokine expression at lactation when compared with virgin control rats, suggesting that adipokine expression is not related to BAT adaptations. During pregnancy, some changes in adipokine expression were observed in BAT. The change seen in leptin mRNA was not as great as that reported by Frontera et al. (2005) and there is no other published information on adipokine expression in BAT during 
pregnancy. In the present study the different patterns of expression of the adipokines, except for apelin, between BAT and WAT suggest that their expression is regulated differentially in these tissues. At this stage, the significance of adipokine expression in BAT is not known.

It remains to be determined what mechanisms are responsible for the marked up-regulation of FIAF mRNA expression and the patterns of change in apelin, visfatin and RBP4 mRNA expression. The main candidates are pregnancy hormones, oestrogen, progesterone, placental lactogens and prolactin. Studies will need to be done to determine whether the changes are due directly to pregnancy hormones or as a secondary consequence. Further investigations are needed to determine whether FIAF is a major factor contributing to the adaptations of normal pregnancy, and in particular to confirm that the increase in FIAF mRNA is accompanied by a corresponding increase in plasma concentrations of FIAF. Additional studies will need to be done to determine whether any of these adipokines are involved in pathologies of pregnancy such as gestational diabetes. To date there is no information about this for FIAF, apelin and RBP4 and the limited information for visfatin has been contradictory (Chan et al. 2006, Krzyzanowska et al. 2006). Understanding what brings about the changes in insulin sensitivity and metabolism that occur in pregnancy and lactation may also help provide insights into the underlying pathologies of obesity and its associated disorders such as type 2 diabetes.

\section{Funding}

This study was funded in part by a grant from the Otago Medical School Research Bequest Fund to Mary Thompson and David Grattan. The authors declare that there is no conflict of interest that would prejudice the impartiality of this scientific work.

\section{References}

Amico JA, Thomas A, Crowley RS \& Burmeister LA 1998 Concentrations of leptin in the serum of pregnant, lactating and cycling rats and of messenger ribonucleic acid in rat placental tissues. Life Sciences 63 1387-1395.

Bing C, Gomez-Ambrosi J, Zabalegui N, Williams G \& Trayhurn P 2002 Resistin and RELM- $\alpha$ gene expression in white adipose tissue of lactating mice. Biochemical and Biophysical Research Communications 296 458-462.

Boucher J, Masri B, Daviaud D, Gesta S, Guigné C, Mazzucotelli A, CastanLaurell I, Tack I, Knibiehler B, Carpéné C et al. 2005 Apelin, a newly identified adipokine up-regulated by insulin and obesity. Endocrinology 146 1764-1771.

Buettner R, Newgard CB, Rhodes CJ \& O'Doherty RM 2000 Correction of diet-induced hyperglycemia, hyperinsulinemia, and skeletal muscle insulin resistance by moderate hyperleptinemia. American Journal of Physiology. Endocrinology and Metabolism 278 E563-E569.

Butte NF, Hopkinson JM \& Nicolson MA 1997 Leptin in human reproduction: serum leptin levels in pregnant and lactating woman. Journal of Clinical Endocrinology and Metabolism 82 585-589.
Caja S, Martínez I, Abelenda M \& Puerta M 2005a Resistin expression and plasma concentration peak at different times during pregnancy in rats. Journal of Endocrinology 185 551-559.

Caja S, Torrente M, Martinez I, Abelenda M \& Puerta M $2005 b$ Adiponectin values are unchanged during pregnancy in rats. Journal of Endocrinological Investigation 28 609-615.

Catalano PM, Hoegh M, Minium J, Huston-Presley L, Bernard S, Kalhan S \& Hauguel-De Mouzon S 2006 Adiponectin in human pregnancy: implications for the regulation of glucose lipid metabolism. Diabetologia 49 $1677-1685$.

Chan TF, Chen YL, Lee CH, Chou FH, Wu LC, Jong SB \& Tsai EM 2006 Decreased plasma visfatin concentrations in women with gestational diabetes mellitus. Journal of the Society for Gynecologic Investigation 13 364-367.

Chein EK, Hara M, Rouard M, Yano H, Phillippe M, Polonsky KS \& Bell GI 1997 Increase in serum leptin and uterine leptin receptor messenger RNA levels during pregnancy in rats. Biochemical and Biophysical Research Communications 237 476-480.

Chen MP, Chung FM, Chang DM, Tsai JC, Huang HF, Shin SJ \& Lee YL 2006 Elevated plasma levels of visfatin/pre-B cell colony-enhancing factor in patients with type 2 diabetes mellitus. Journal of Clinical Endocrinology and Metabolism 91 295-299.

Cho YM, Youn BS, Lee H, Min SS, Kwak SH, Lee HK \& Park KS 2006 Plasma retinol binding protein-4 concentrations are elevated in human subjects with impared glucose tolerance and type 2 diabetes. Diabetes Care $292457-2461$.

Combs TP, Berg AH, Rajala MW, Klebanov S, Iyengar P, Jimenez-Chillaron JC, Patti ME, Klein SL, Weinstein RS \& Scherer PE 2003 Sexual differentiation, pregnancy, calorie restriction and aging affect the adipocytespecific secretory protein adiponectin. Diabetes $\mathbf{5 2}$ 268-276.

Di Cianni G, Miccoli R, Volpe L, Lencioni C \& Del Prato S 2003 Intermediate metabolism in normal pregnancy and in gestational diabetes. Diabetes/Metabolism Research and Reviews 19 259-270.

Frontera M, Pujol E, Rodríguez-Cuenca S, Catala-Neill A, Roca P, Garcia-Palmer FJ \& Gianotti M 2005 Rat brown adipose tissue thermogenic features are altered during mid-pregnancy. Cellular Physiology and Biochemistry 15 203-210.

Fukuhara A, Matsuda M, Nishizawa M, Segawa K, Tanaka M, Kishimoto K, Matsuki Y, Murakami M, Ichisaka T, Murakami H et al. 2005 Visfatin: a protein secreted by visceral fat that mimics the effects of insulin. Science $\mathbf{3 0 7}$ 426-430.

García MC, Casanueva FF, Diéguez C \& Seañís RM 2000 Gestational profile of leptin messenger ribonucleic acid (mRNA) content in the placenta and adipose tissue in the rat, and regulation of the mRNA levels of the leptin receptor subtypes in the hypothalamus during pregnancy and lactation. Biology of Reproduction 62 698-703.

Graham TE, Yang Q, Blüher M, Hammarstedt A, Ciaraldi TP, Henry RR, Wason CJ, Oberbach A, Jansson P, Smith U et al. 2006 Retinol-binding protein 4 and insulin resistance in lean, obese and diabetic subjects. New England Journal of Medicine 354 2552-2563.

Henson MC \& Castracane VD 2000 Leptin in pregnancy. Biology of Reproduction 63 1219-1228.

Herrera E 2000 Metabolic adaptations in pregnancy and their implications for the availability of substrates to the fetus. European Journal of Clinical Nutrition 54 S47-S51.

Herrera E, Lasunción MA, Huerta L \& Martin-Hidalgo A 2000 Plasma leptin levels in the rat mother and offspring during pregnancy and lactation. Biology of the Neonate 78 315-320.

Kautzky-Willer A, Pacini G, Tura A, Bieglmayer C, Schneider B, Ludvik B, Prager R \& Waldhausl W 2001 Increased plasma leptin in gestational diabetes. Diabetologia 44 164-172.

Kawai M, Yamaguchi M, Murakami T, Shima K, Murata Y \& Kirshi K 1997 The placenta is not the main source of leptin production in pregnant rats: gestational profile of leptin in plasma and adipose tissues. Biochemical and Biophysical Research Communications 240 798-802.

Kersten S, Mandard S, Tan NS, Escher P, Metzger D, Chambon P, Gonzalez FJ, Desvergne B \& Wahli W 2000 Characterisation of the fasting-induced adipose factor FIAF, a novel peroxisome poliferator-activated receptor target gene. Journal of Biological Chemistry 275 28488-28493. 
Kim I, Kim HG, Kim H, Kim HH, Park SK, Uhm C, Lee ZH \& Koh GY 2000 Hepatic expression, synthesis and secretion of novel fibrinogen/ angiopoietin-related protein that prevents endothelial-cell apoptosis. Biochemical Journal 346 603-610.

Kim K, Lee K, Moon YS \& Sul HS 2001 A cysteine rich adipose tissue specific secretory factor inhibits adipocyte differentiation. Journal of Biological Chemistry 276 11252-11256.

Kondo E, Sugiyama T, Kusaka H \& Toyoda N 2004 Adiponectin mRNA levels in parametrial adipose tissue and serum adiponectin levels are reduced in mice during late pregnancy. Hormone and Metabolic Research 36 465-469.

Krzyzanowska K, Krugluger W, Mittermayer F, Rahman R, Haider D, Shnawa N \& Schernthaner G 2006 Increased visfatin concentrations in women with gestational diabetes mellitus. Clinical Science 110 605-609.

Ladyman SR \& Grattan DR 2004 Region-specific reduction in leptininduced phosphorylation of signal transducer and activator of transcription3 (STAT3) in the rat hypothalamus is associated with leptin resistance during pregnancy. Endocrinology 145 3704-3711.

López-Soriano J, Carbó N, López-Soriano J \& Argilés JM 1998 Leptin levels and gene expression during the perinatal phase in the rat. European Journal of Obstetrics and Gynecology 81 95-100.

Mandard S, Zandbergen F, van Straten E, Wahli W, Kuipers F \& Müller M 2006 The fasting-induced adipose factor/angiopoietin-like protein 4 is physically associated with lipoproteins and governs plasma lipid levels in adiposity. Journal of Biological Chemistry 281 934-944.

Mistry AM \& Romsos DR 2002 Intracerebroventricular leptin administration reduces food intake in pregnant and lactating mice. Experimental Biology and Medicine 227 616-619.

Mukherjea R, Castonguay TW, Douglass LW \& Moser-Veillon P 1999 Elevated leptin concentrations in pregnancy and lactation: possible role as a modulator of substrate utilization. Life Sciences 11 1183-1193.

Nogueiras R, Gualilo O, Caminos JE, Casanueva FF \& Diéguez C 2003 Regulation of resistin by gonadal, thyroid hormone, and nutritional status. Obesity Research 11 408-414.

Ramos MP, Crespo-Solans MD, del Campo S, Cacho J \& Herrera E 2003 Fat accumulation in the rat during early pregnancy is modulated by enhanced insulin responsiveness. American Journal of Physiology. Endocrinology and Metabolism 285 E318-E328.

Reitman ML, Bi S, Marcus-Samuels B \& Garilova O 2001 Leptin and its role in pregnancy and fetal development - an overview. Biochemical Society Transactions 29 68-72.

Ronti T, Lupattelli G \& Mannarino E 2006 The endocrine function of adipose tissue: an update. Clinical Endocrinology 64 355-365.

Seeber RM, Smith JT \& Waddell BJ 2002 Plasma leptin-binding activity and hypothalamic leptin receptor expression during pregnancy and lactation in the rat. Biology of Reproduction 66 1762-1767.

Steppan CM, Bailey ST, Bhat S, Brown EJ, Banerjee RR, Wright CM, Patel HR, Ahima RS \& Lazar MA 2001 The hormone resistin links obesity to diabetes. Nature 409 307-312.
Thyfault JP, Hedberg EM, Anchan RM, Thorne OP, Isler CM, Newton ER, Dohm CL \& deVente JE 2005 Gestational diabetes is associated with depressed adiponectin levels. Journal of the Society for Gynecologic Investigation 12 41-45.

Tomimatsu T, Yamaguchi M, Murakami T, Ogura K, Sakata M, Mitsuda N, Kanzaki T, Kurachi H, Irahara M, Miyake A et al. 1997 Increase of mouse leptin production by adipose tissue after midpregnancy: gestational profile of serum leptin concentration. Biochemical and Biophysical Research Communications 240 213-215.

Trayhurn P 2005 Endocrine and signaling role of adipose tissue: new perspectives on fat. Acta Physiologica Scandinavica 184 285-293.

Trayhurn P, Douglas JB \& McGuckin MM 1982 Brown adipose thermogenesis is suppressed during lactation in mice. Nature 298 59-60.

Weyer C, Funahashi T, Tanaka S, Hotta K, Matsuzawa Y, Pratley RE \& Tataranni A 2001 Hypoadiponectinemia in obesity and type 2 diabetes: close association with insulin resistance and hyperinsulinemia. Journal of Clinical Endocrinology and Metabolism 86 1930-1935.

Williamson DH \& Lund P 1994 Cellular mechanisms for the regulation of adipose tissue lipid metabolism in pregnancy and lactation. Advances in Experimental Medicine and Biology 352 45-70.

Worda C, Leipold H, Gruber C, Kautzky-Willer A, Knöfler M \& Bancher-Todesca D 2004 Decreased plasma adiponectin concentrations in woman with gestational diabetes mellitus. American Journal of Obstetrics and Gynecology 191 2120-2124.

Xu A, Lam MC, Chang KW, Wang Y, Zhang J, Hoo RL, Xu JY, Chen B, Chow W, Tso AWK et al. 2005 Angiopoietin-like protein 4 decreases blood glucose and improves glucose tolerance but induces hyperlipidemia and hepatic steatosis in mice. PNAS 102 6086-6091.

Yang Q, Graham TE, Mody N, Preitner F, Peroni OD, Zabolotny JM, Kotani K, Quadro L \& Kahn BB 2005 Serum retinol binding protein 4 contributes to insulin resistance in obesity and type 2 diabetes. Nature 436 356-362.

Yoon JC, Chickering TW, Rosen ED, Dussault B, Qin Y, Soukas A, Friedman JM, Holmes WE \& Spiegelman BM 2000 Peroxisome proliferator-activated receptor $\gamma$ target gene encoding a novel angiopoietin-related protein associated with adipose differentiation. Molecular and Cellular Biology 20 5343-5349.

Yoshida K, Shimizugawa T, Ono M \& Furukawa H 2002 Angiopoietin-like protein 4 is a potent hyperlipidemia-inducing factor in mice and inhibitor of lipoprotein lipase. Journal of Lipid Research 43 1770-1772.

Zhang Y, Matheny M, Zolotukhin S, Tumer N \& Scarpace PJ 2002 Regulation of adiponectin and leptin gene expression in white and brown adipose tissues: influence of the $\beta 3$-adrenergic agonists, retinoic acid, leptin and fasting. Biochemica et Biophysica Acta 1584 115-122.

Received in final form 8 May 2007

Accepted 19 May 2007

Made available online as an Accepted Preprint

21 May 2007 